\title{
LIBROS RECIBIDOS
}

AA.VV.: Une communauté de droit - Festschrift für Gil Carlos Rodríguez Iglesias, Berliner Wissenschafts-Verlag, Berlin 2003, 648 pp.

AA.VV.: La ampliación europea: desafios y oportunidades, Federación de Cajas de Ahorros Vasco-Navarras, Vitoria, 2003, $258 \mathrm{pp}$.

AA.VV.: Europa ante su futuro. Una visión desde Euskadi, Bilbao, Consejo Vasco del Movimiento Europeo, 2004, 234 pp.

Anuario de Derecho Europeo, n..$^{\circ}$ 3, Universidad de Sevilla, 2003, 341 pp.

BAQUERO CRUZ, J.: Entre competencia y libre circulación - El derecho constitucional económico de la Comunidad Europea, Civitas, Madrid 2002, 293 pp.

C.E.D.E.: La gestion des déchets dans les îles au regard du droit communautaire, Funchal, C.E.D.E., 2004, 113 pp.

Cebada Romero, A.-PÉrez González, C.: El Alto Representante de la PESC y la nueva Política Europea de Seguridad y Defensa, Dykinson, Madrid, 2003, $160 \mathrm{pp}$.

JiMÉNEZ PIERNAS (ed.): Iniciación a la práctica en Derecho Internacional y Derecho Comunitario Europeo, Universidad de Alcalá-Marcial Pons, 2003, 676 pp.

PETSChEN Verdaguer, S. (Coord.): El papel de las Regiones en Europa, Biblioteca Nueva, Madrid, 2003, $158 \mathrm{pp}$.

ZaPatero Miguel, P.: Derecho del comercio global, Civitas, Madrid 2003, 627 pp. 


\title{
RECENSIONES
}

\author{
Álvarez Verdugo, M.: La política de seguridad y defensa en la Unión Europea, \\ Madrid, Dykinson, 2003, 304 pp.
}

Pese a lo que su título parece indicar, la obra que ahora reseñamos no versa únicamente sobre este nuevo objeto de deseo intelectual en que se ha convertido para el observador el proceso de integración en estos últimos años la denominada política europea de seguridad y defensa. Tras ese título encontramos algo más; encontramos el resultado de un ambicioso esfuerzo de reflexión sobre el conjunto de problemas que suscitan la seguridad y la defensa en esta época de profundas transformaciones en el continente europeo. No en vano el contenido de esta publicación trae su causa de la tesis doctoral defendida por su autora en la Universidad de Barcelona en el año 2000. Un trabajo de investigación que ha debido ser completamente actualizado antes de su envío a la editorial, habida cuenta de la aceleración que en este intervalo de tiempo ha conocido el proceso de construcción de la PESD. Doble mérito, por tanto, el de la Dra. Álvarez Verdugo.

La estructura de la obra refleja claramente esa pretensión de trascender el análisis de estos últimos desarrollos, ciertamente espectaculares y hasta vertiginosos, que se han producido en el seno de la UE. Comienza, en efecto, con un amplio capítulo dedicado a desentrañar el significado y alcance de las nociones de seguridad y defensa en la Europa de la posguerra fría, y concluye con otro, no menos extenso, en el que se estudia con detalle el papel desempeñado por la OTAN en la configu- ración de la nueva política europea en este campo. Los dos capítulos restantes se centran, como es lógico, en el análisis específico de la PESD.

La reflexión inicial está justificada, a juicio de la autora, no sólo por la evidente mutación de los riesgos que amenazan la seguridad europea, sino también y principalmente por el hecho de que la política de seguridad y defensa de la UE no incluye hoy por hoy el compromiso básico de asistencia mutua frente a un ataque armado con el que tradicionalmente se ha identificado la noción de defensa en la esfera internacional. Ésta sería la acepción funcional del término defen$\mathrm{sa}$, en franco declive ante la emergencia de una nueva acepción organizativa de la misma, en el sentido en el que esta diferenciación ha sido acuñada por la doctrina política. La diversificación de tareas que esta concepción trae aparejada ha provocado un solapamiento entre los ámbitos de actuación de las organizaciones europeas con responsabilidades en el campo de la defensa, que se han visto obligadas a articular mecanismos de cooperación entre ellas para desempeñar adecuadamente su cometido. Es la noción de «seguridad cooperativa», a través de la cual la Dra. Álvarez Verdugo interpreta la actual arquitectura europea de defensa y analiza sus relaciones con el sistema universal de seguridad colectiva, fundamentalmente en lo que atañe a la aplicación de medidas coercitivas que impliquen el uso de la fuerza armada.

Descendiendo ya el terreno concre- 
to de la UE, en el capítulo segundo se procede a delimitar, a la luz de las categorías generales anunciadas con anterioridad, el sentido y alcance de la cooperación entablada en su seno por los Estados miembros en materia de seguridad y defensa. Se trata de un capítulo de transición en el conjunto de la obra, mucho más breve que el resto y que sirve para conducirnos hacia el análisis de los entresijos de la PESD. Aquí radica, sin duda, otro de los aspectos más originales del trabajo, puesto que el enfoque adoptado a este respecto en el capítulo tercero es esencialmente institucional. En efecto, a lo largo de sus casi cien páginas encontramos un excelente estudio del marco institucional de la PESD: de sus nuevos órganos, del papel que en su seno desempeñan las instituciones de la Unión, así como de la participación de unos y otras en el complejo proceso de decisión previsto por el Tratado y de la naturaleza jurídica de los distintos tipos de actos que pueden ser adoptados en virtud del mismo. Incluso el análisis previo de la transformación experimentada por la UEO durante los años noventa y el posterior de los nuevos medios operativos al servicio de la PESD que completan este capítulo, están teñidos también por ese enfoque institucional. Algo no sólo original, sino muy meritorio atendiendo a la envergadura de los problemas jurídicos a los que la autora se enfrenta con éxito en esta parte de la obra.

El cuarto y último capítulo está dedicado, en fin, a la incidencia que la Alianza Atlántica ha tenido en el proceso de construcción de la PESD. Es bien sabido que éste ha sido uno de los factores que en mayor medida ha condicionado y complicado el desarrollo de esta política, entre otras razones, por la preexistencia de un peculiar esquema de relaciones entre la UEO y aquélla organización. No debe extrañar, pues, que para comprender el nuevo marco de relaciones UE-OTAN la autora se interese antes por la vinculación que durante décadas de la UEO mantuvo con la Alianza. Aunque tal vez debería haberlo hecho procurando guardar un mayor equilibrio entre el análisis de ambos modelos de relación, ya que centra su atención esencialmente en este último. Los plazos de entrega del trabajo a la editorial le impidieron, sin duda, adentrarse de un modo más detallado en el estudio de los mecanismos finalmente acordados por la UE y la OTAN en diciembre de 2002 para garantizar el acceso de la primera a los medios y capacidades militares de la segunda.

Con cierta modestia o timidez, la Dra. Álvarez Verdugo denomina en último término «Consideraciones finales» lo que, por su contundencia y brillantez, son en realidad auténticas conclusiones de la obra. Y es que en ellas sintetiza de modo muy convincente los argumentos que avalan un postulado que, no por conocido, deja de resultar provocador: pese a todo, «la configuración de la PESD revela la incapacidad de la UE para, en el actual momento de desarrollo del proceso de integración europea, asumir un papel político relevante en la escena internacional» (p. 284).

Luis N. González Alonso, U. Salamanca 
Broberg, M. P.: The European Commission's Jurisdiction to Scrutinise Mergers, 2. ${ }^{a}$ edición, Kluwer, Deventer, 2003. 445 pp.

Dentro de la colección European Monographs de la editorial Kluwer, se ha publicado la segunda edición de la obra del danés Morten P. Broberg dedicada a la jurisdicción de la Comisión Europea en el control de las operaciones de concentración entre empresas.

A primera vista, la fecha de su publicación -marzo de 2003- puede Ilevar al lector a considerar carente de interés un estudio sobre el examen ejercido por la Comisión al amparo del Reglamento 4064/89. En efecto, la obra es anterior a la reciente reforma del Reglamento - sólo tiene en cuenta la propuesta de la Comisión de diciembre de 2002-, por lo que su oportunidad temporal puede ser fácilmente cuestionada. No obstante, es preciso recordar que el nuevo Reglamento 139/2004 introduce modificaciones que afectan fundamentalmente a los aspectos sustantivos y procedimentales del control de las operaciones de concentración, sin apenas alterar lo establecido por el Reglamento $4064 / 89$ con relación a las cuestiones competenciales o de jurisdicción (es decir, los artículos 1.2 y 1.3 , relativos a los umbrales de los volúmenes de negocios, no han sido modificados). Es a estas cuestiones que Broberg dedica su monografía, estructurada en nueve capítulos que analizan los diferentes aspectos de la noción clave en la determinación de la jurisdicción de la Comisión, la noción de «dimensión comunitaria», que sirve para definir la jurisdicción de la Comisión Europea en materia de control de concentraciones entre empresas.

A pesar de que el antiguo y el nuevo Reglamento sobre el control de concentraciones proporcionan los criterios necesarios para definir qué operaciones son competencia de la Comisión, la delimitación de la jurisdicción continúa creando problemas importantes, como han puesto de manifiesto las sentencias del Tribunal de Primera Instancia de las Comunidades Europeas anulando las Decisiones de la Comisión en los asuntos Tetra Laval, Schneider y Airtours. En este sentido, la segunda edición de The European Commission's Jurisdiction to Scrutinise Mergers ofrece un análisis comprensivo y actualizado de los diferentes aspectos de esta delimitación, conceptos todos de vigencia intemporal.

Después de un primer capítulo introductorio -donde Broberg, entre otras cosas, describe de manera concisa la denominada regla de la «ventanilla única) (o one-stop-shop) y sus excepciones--, el libro avanza, capítulo por capítulo, analizando todos y cada uno de los criterios necesarios para decidir en quién recae la competencia para examinar una operación de concentración.

Así, dado que la dimensión comunitaria se calcula sobre la base del volumen de negocios de las empresas afectadas por la operación, el capítulo segundo se ocupa de examinar la noción de «empresas afectadas» utilizada en el Reglamento y de compararla con la interpretación realizada por la Comisión en su Comunicación sobre el concepto de empresas afectadas y en sus decisiones, con especial mención del caso British Airways/Dan Air. De igual manera, dado que los dos grupos de umbrales de volumen de negocios que definen el alcance de la aplicación del Reglamento se basan, no en el volumen individual de cada una de las empresa afectadas, 
sino en el volumen total de los grupos a los que éstas pertenecen, Broberg dedica el capítulo tercero a estudiar el término «grupo» y su definición en relación con la noción de control.

Una vez determinadas las empresas afectadas, así como identificados los respectivos grupos a que éstas pertenecen, llega el momento de calcular los correspondientes volúmenes de negocios. Broberg señala acertadamente en el capítulo cuarto que, a pesar de que el criterio del cálculo de los umbrales fue elegido porque se consideró un parámetro relativamente neutral para evaluar la dimensión comunitaria de una operación de concentración, la práctica puede dar lugar a ambigüedades. De esta forma, el autor proporciona pautas de gran utilidad sobre cómo proceder al cálculo: cuentas que deben ser utilizadas, actividades que deben ser incluidas, tratamiento que debe otorgarse a los impuestos y descuentos, cómo hacer la conversión en euros y cómo resolver los problemas relacionados con las ventas dentro del grupo.

De especial interés resulta el capítulo quinto, dedicado al reparto geográfico del volumen de negocios. Dado que no existe ninguna guía sustancial relativa al reparto geográfico del volumen de negocios en el Reglamento, ni en la Comunicación de la Comisión relativa al cálculo del volumen de negocios, y a pesar de que se trata de un tema recurrente en las decisiones de la Comisión sobre operaciones de concentración y en la literatura jurídica, suele resultar complicado deducir directrices claras de estas fuentes. Broberg trata pues de identificar soluciones factibles dentro del marco legal del Reglamento. Así, se centra en la «venta relevante», en el reparto geográfico del volumen con re- ferencia a productos tangibles y servicios, así como en los cambios producidos en el territorio comunitario.

Los cuatro últimos capítulos se centran en la determinación de la jurisdicción sobre el control de concentraciones entre empresas pertenecientes al sector financiero y entre empresas presentes en el Espacio Económico Europeo; en el denominado forum shopping (posibilidad de las partes de elegir la jurisdicción encargada de examinar la operación); y en la «verdadera dimensión comunitaria». Éste noveno y último capítulo resulta especialmente interesante, pues Broberg examina los límites externos (con referencia al caso Gencor) e internos del Reglamento de concentraciones, analizando si los umbrales de volumen de negocios proporcionan una definición apropiada de la «verdadera dimensión comunitaria», señalando los problemas inherentes a la definición actual de la dimensión comunitaria conforme al Reglamento, y proponiendo soluciones y recomendaciones para mejorar la delimitación de jurisdicción con arreglo al sistema actual.

Cinco años separan esta edición de su predecesora, que se basaba en la tesis doctoral de este investigador del Centro de Estudios Internacionales y Europeos de la Universidad Robert Schuman (Estrasburgo), del Instituto Max-Planck (Munich) y de la Universidad de Copenhague. Pero no estamos sólo ante una versión actualizada de la primera, sino ante una valiosa profundización práctica en una de las nociones centrales del control de concentraciones comunitario.

$$
\begin{array}{r}
\text { L. Ortiz Blanco } \\
\text { y } M \cdot^{a} \text { Fernández Molinero, } \\
\text { Garrigues Abogados }
\end{array}
$$


Carrera Hernández, F. J., La cooperación policial en la Unión Europea: Acervo de Schengen y Europol, Ed. Colex, Madrid, 2003, 207 pp.

La mayor integración en la cooperación entre las fuerzas de seguridad de los Estados miembros de la Unión Europea, representa, actualmente, uno de los elementos más sobresalientes en la nueva etapa surgida a partir del Tratado de Ámsterdam. En efecto, con las modificaciones introducidas en el TUE en la capital holandesa, se inserta en el texto del Tratado la noción de Espacio de Libertad, Seguridad y Justicia, en el que esté garantizado «la libre circulación de personas conjuntamente con medidas adecuadas respecto al control de las fronteras exteriores, el asilo, la inmigración y la prevención y la lucha contra la delincuencia» (Art. 2 TUE).

En este nuevo ámbito de cooperación intergubernamental, es digno de mención la labor de análisis desarrollada por el Dr. Carrera Hernández, Profesor Titular de Derecho Internacional Público (Derecho Comunitario Europeo) de la Universidad de Salamanca, el cual, en la presente monografía, realiza un brillante recorrido por la evolución jurídica y práctica de la cooperación policial entre los Estados miembros. Su trabajo constituye una herramienta esencial de conocimiento y claridad para aquellos que deseen adentrarse, por primera vez, en el estudio de tan delicado aspecto de la soberanía nacional como es la lucha contra la delincuencia organizada en un sentido amplio.

La monografía del Dr. Carrera Hernández podría ser estructurada en cuatro bloques claramente identificativos. En el primero de ellos, que correspondería con el Capítulo primero, se recoge de forma precisa la evolución de la cooperación policial desde sus orígenes en los años setenta hasta su mayor integración con el surgimiento del Espacio de Libertad, Seguridad y Justicia, haciendo referencia al papel fundamental que ha jugado los Acuerdos de Schengen en esta materia. De este modo, se resalta el nacimiento de la cooperación policial en un ámbito iusinternacionalista sin vínculo alguno con el Derecho comunitario, si bien persiguiendo en último término unos fines similares a los recogidos en el TUE. Un segundo bloque, formado por los Capítulos segundo, tercero y cuarto, representaría el núcleo duro del trabajo del Dr. Carrera Hernández. En estos tres Capítulos, se procede a la descripción jurídico-institucional de la cooperación policial a partir del articulado del TUE, con especial tratamiento de la comunitarización del Acervo Schengen en esta materia y las cuestiones de base jurídica que han surgido a partir de su absorción por el Derecho de la UE. La labor del Dr. Carrera Hernández aporta claridad en la comprensión de las materias de cooperación policial en el TUE. El tercer bloque, representado por los Capítulos quinto y sexto, se identifican con la aplicación operativa de esta cooperación policial. En efecto, y diferenciando brillantemente la cooperación directa de la cooperación en el seno de la Europol, este tercer bloque describe de forma sencilla y comprensible las modalidades de cooperación entre los cuerpos y fuerzas de seguridad de los Estados miembros. Si bien se recogen cuestiones interesantes como son la llamada persecución en caliente o las relaciones de Europol con terceros Estados, se 
puede echar en falta alguna referencia a la aplicación práctica de esta cooperación, en particular aquella en la que hayan participado los Cuerpos de Seguridad españoles. No obstante, debemos ser justos con el autor y alabar, con la máxima consideración, su opción de limitarse a la descripción de las posibilidades reales de una incipiente integración de los cuerpos policiales de los Estados miembros. Finalmente, el último bloque estaría constituido por un Anexo documental que, comprendiendo casi 100 páginas, aporta las principales normas adoptadas en el ámbito de la cooperación policial y que constituyen una herramienta fundamental para una comprensión más completa de la obra.
En definitiva, la labor desarrollada por los iusinternacionalistas de la Universidad de Salamanca en el estudio de la cooperación intergubernamental en materia policial queda patente con la obra del Dr. Carrera Hernández. En línea con las palabras de la Dra. Mangas Martín recogidas en el prólogo, la presente obra aporta un estudio completo, sucinto y claro respecto a la acción y a la normativa que, sobre cooperación policial europea, se ha desarrollado en el ámbito comunitario, representando una herramienta esencial para aquellos que deseen adentrarse en tan delicada materia.

M. A. Acosta, U. cádiz

C.E.D.E.: La gestion des déchets dans les îles au regard du droit communautaire, Funchal, 2004, 113 pp.

El volumen tercero de la Serie Azul publicado por el Consejo Europeo de Derecho del Medio Ambiente está dedicado a un tema especialmente complejo y sensible como es el tratamiento de los residuos en islas respecto del Derecho Comunitario. Es lógico que la mencionada institución, consagrada al desarrollo del estudio del derecho medioambiental en el marco europeo, manifieste una especial sensibilidad respecto de los problemas ambientales que se suscitan en islas u otras regiones ultraperiféricas siendo que su sede social se encuentra en Funchal (Madeira), y así su vigésima Resolución (de 4 de mayo de 2001) versó sobre una propuesta de estrategia para la cooperación entre las regiones autónomas de Madeira, Azores e Islas Canarias para la protección del medio ambiente.
Lo cierto es que estos territorios, por definición alejados del territorio continental, presentan importantes divergencias y singularidades entre ellos, no sólo desde un punto de vista geográfico sino también administrativo, pero, a su vez, comparten un conjunto de problemas medioambientales comunes derivado de sus altas tasas de desarrollo en los últimos años, difícilmente calificable como sostenible en la gran mayoría de los casos, ya que, tratándose de ecosistemas circunscritos a un territorio aislado, manifiestan una gran vulnerabilidad. El desarrollo turístico es, por ejemplo, en la mayoría de los casos, una clara muestra al respecto.

En este sentido, el tratamiento de residuos, (ya tratado en la Resolución decimonovena del C.E.D.E. de $16 \mathrm{de}$ diciembre de 2000, Resolución sobre la 
gestión de residuos en las regiones ultraperiféricas de la Unión Europea), representa problemas específicos para el conjunto de las islas, lo que hace necesario adaptar a sus peculiaridades geográficas el conjunto de normas europeas sobre la materia. Efectivamente, en general bajo el enfoque del principio de subsidiaridad y de proporcionalidad, se examinan en el presente trabajo toda una legislación compleja y técnica que se ha venido desarrollando en el marco europeo sobre residuos, adaptando los principales principios de derecho medioambiental, tanto en lo relativo a los diferentes métodos de eliminación de residuos, medidas y principios económicos, y finalmente, su desarrollo o aplicación por parte de sistemas administrativos regidos por esquemas unas veces, centralizados, y otras, descentralizados.

La presente obra se inicia con un trabajo de Isabelle Trinquelle, experta del C.E.D.E., consultora medioambiental, bajo el título «La spécificité de la gestion des déchets dans les îles au regard du droit communautaire» (p. 15). Este trabajo presenta un enfoque global respecto de la gestión de residuos en el derecho comunitario, partiendo de su valor como símbolo del producto de un crecimiento económico, que debe a su vez armonizarse con la protección del medio ambiente. A este fin, en primer lugar, la Dra. Trinquelle analiza la necesidad de justificación de medidas específicas a favor de las islas y el reconocimiento de las especificidades territoriales en los tratados constitutivos de la Comunidad Europea para finalizar con un estudio detallado de la naturaleza y extensión de las medidas específicas previstas en el derecho europeo y los mecanismos que posibili- tan su aplicación por los Estados Miembros.

Con un contenido esencialmente técnico, Elisabeth Olival, ingeniero, se ocupa de la «Gestion des déchets ménagers et gestion des emballages et déchets d'emballages dans les régions ultrapériphériques» (p. 51). Efectivamente, es en el tratamiento de residuos urbanos y envases donde, en mayor medida, se aprecian los problemas derivados de las características geográficas de los territorios ultraperiféricos, alejados del territorio continental con gran dependencia respecto del exterior y con los sobrecostes que implica la necesaria importación de tecnologías y equipamientos en regiones de débil componente industrial de su estructura económica. Este trabajo pone de manifiesto la situación de los sistemas de gestión de los residuos urbanos en las regiones ultraperiféricas, caracterizadas en general, por su retraso respecto de la estrategia europea, que se encuentran todavía en la actualidad intentando erradicar la práctica de vertidos incontrolados, adecuándose a los sistemas continentales de tratamiento y eliminación.

Los dos últimos trabajos de la presente obra tienen en común su enfoque territorialmente limitado, analizando dos supuestos no sólo alejados geográficamente, sino también en su organización administrativa; descentralizada, en el caso de las Islas Canarias, centralizada, en las islas griegas, con la consiguiente proyección sobre el modelo de gestión de residuos.

El profesor Herrero de la Fuente presenta un trabajo relativo a la aplicación de la normativa comunitaria relativa a residuos en las Islas Canarias (p. 75, «La mise en oeuvre de la réglementation communautaire relative aux déchets dans les îles Canaries»), representando éstas un 
supuesto típico de los problemas a los que hemos venido mencionando, alejadas del territorio continental, habiendo sufrido una profunda transformación desde una economía basada tradicionalmente en el sector primario a una economía apoyada en un desarrollo turístico masivo. Así, partiendo de la problemática singular canaria, desglosa el marco nacional con gran claridad para concluir en la legislación autónoma canaria y su puesta en practica a través del Plan Integral de Residuos de Canarias y los Planes Directores insulares de Residuos.

Finalmente, en el más breve de los trabajos, Christophe A. Pétrou analiza los problemas específicos de la gestión centralizada de residuos en las islas griegas (p. 95, «La mise en oeuvre de la réglementation hellénique en matière de déchets et les problèmes causés dans les îles grecques»). Destaca especialmente de este trabajo la visión profundamente critica de la situación griega sometida a un modelo intensivo de desarrollo turístico sin infraestructuras adecuadas y con un esquema administrativo ineficaz.

Nos encontramos, en definitiva, ante un volumen valioso en cuanto que enfoca el complejo problema relativo al tratamiento de desechos, circunstancia que conjuga desarrollo económico y respeto del medio ambiente, desde la particular optica de las islas, lo que representa la necesidad de recurrir a las herramientas que proporciona el Derecho Comunitario para su aplicación a situaciones tan específicas y vulnerables.

J. Verdú, CUESA-U. Cádiz

Garcf́a PÉRez, R.: Política de Seguridad y Defensa de la Unión Europea, Madrid, UNED, 2003, 158 pp.

La asunción de nuevas responsabilidades por parte de la Unión Europea en los campos de la seguridad y de la defensa se ha convertido en uno de los aspectos más atractivos y dinámicos de la evolución reciente del proceso de integración; en su «nueva frontera», al decir de observadores muy cualificados, en estos albores del siglo XXI. Se comprende, pues, el interés que ha desertado entre la doctrina, como muestra, entre otras muchas, la obra que ahora presentamos.

Su autor, profesor titular de Relaciones Internacionales en la Facultad de Ciencias Políticas de la Universidad de Santiago de Compostela, se propone y consigue captar en la misma la esencia del complejo proceso de construcción de la política europea de seguridad y defensa, a través del analisis de los esfuerzos desplegados en este sentido por los Estados miembros de la Unión desde finales de los años ochenta. En efecto, con pluma ágil, aunque rigurosa $y$ extremadamente precisa en la redacción, el Dr. García Pérez recorre este período articulando sus reflexiones en torno a las tres etapas que, a su juicio, se han sucedido hasta ahora en el desarrollo de esta nueva política. Podría afirmarse, desde esta perspectiva, que la estructura del trabajo obedece a la de una crónica, pero plena, eso sí, de valiosos elementos de reflexión acerca de las contradicciones del proceso objeto de estudio, asi como de sus profundas implicaciones para el conjunto de la ar- 
quitectura occidental de seguridad y defensa.

Los tres capítulos de que consta la obra van precedidos de unas páginas introductorias en las que el autor recuerda de forma muy concisa, y sólo en la medida de lo estrictamente necesario para situar al lector, los factores que provocan la desaparición durante más de tres décadas de los temas relativos a la seguridad militar y la defensa de la agenda de la integración europea. A partir de aquí, y bajo el título La defensa en la construcción de la Europa política (1989-1997), en el capítulo primero se explica por qué la defensa vuelve a concitar en esta época el interés de los Estados miembros en el marco del proceso de integración y, sobre todo, cómo al final de este período se llega a una situación claramente insatisfactoria al no haberse dotado «a la Unión de la eficacia militar que la inestabilidad continental reclamaba», ni habérsele permitido tampoco «superar la indefinición mantenida desde sus orígenes sobre el dilema planteado respecto de su seguridad» (p. 31). Buena parte de estas páginas están dedicadas, como es lógico, al análisis de los procesos de cambio acaecidos de forma paralela en el seno de la OTAN y de la UEO.

Precisamente, la «liquidación» de esta última organización europea es una de las cuestiones que con mayor detalle estudia el autor en el capítulo segundo, junto al resto de aspectos (nueva estructura orgánica y capacidades tanto civiles como militares) que han caracterizado la puesta en marcha de la PESD en el período 1998-2002, a los que, sin embargo, presta una atención más limitada.

En todo caso, y sin desmerecer en absoluto al excelente análisis llevado a cabo hasta este punto, las reflexiones más comprometidas y sugerentes las encontramos en el capítulo tercero ( $E l$ futuro de la PESD). Es aquí donde el profesor García Pérez se pronuncia, con los trabajos de la Convención como telón de fondo, sobre las que él mismo denomina «tareas pendientes» en el proceso de construcción de la PESD: desde el fortalecimiento a medio y largo plazo de las capacidades militares de los Estados miembros en aquellos sectores en los que se han detectado importantes lagunas hasta la indispensable reestructuración de la industria europea de la defensa, pasando por otro tipo de cuestiones como las relativas al control democrático y a la financiación de esta nueva faceta de la acción exterior de la UE. Todas ellas deberían abordarse, a juicio del autor, de forma decidida y con el objetivo de reafirmar la visión europea de la seguridad en un contexto caracterizado por la creciente fractura transatlántica; retomando las palabras con las que cierra su trabajo; «una vez puesta en marcha la dimensión militar de la que carecía la Unión, el objetivo debe ser repolitizar con urgencia la defensa, insertándola, en su justa medida, como un instrumento más entre los muchos de que la UE dispone para la ejecución de una política exterior nueva y reforzada».

Estamos, en definitiva, ante una valiosa aportación doctrinal, que si bien resulta recomendable con carácter general, tal vez lo sea especialmente, habida cuenta de su claridad y estructura interna, para aquellos que se acercan por vez primera al estudio de la PESD.

Luis N. González Alonso 
LiÑÁN NOGUERAS, D. J. (Dir.), C. LóPEZ-JuRADo (Coord.): La reforma de la delimitación competencial en la futura Unión Europea, Editorial Universidad de Granada, Granada, 2003, 349 pp.

Nos encontramos ante una obra colectiva realizada por consagrados especialistas en derecho comunitario, de una categoría científica más que contrastada. En un ámbito jurídico como el europeo, en el que proliferan las aportaciones de neoconversos, que abordan el estudio de esta disciplina sin la suficiente preparación, y sin el debido respeto, se agradecen las contribuciones serias de los que de verdad saben. Este libro recoge fundamentalmente las intervenciones que se realizaron en un Seminario con el mismo título, que tuvo lugar en la Universidad de Granada en noviembre de 2002.

Considero especialmente lúcida la organización de la obra. Ésta se divide en una primera parte, en la que se analiza el sistema competencial comunitario desde una perspectiva general, una segunda parte relativa a la delimitación vertical de competencias en los sectores materiales más problemáticos (este bloque será menos apreciado por aquellos sectores del iusinternacionalismo español que todavía no acaban de entender la relevancia científica y social del derecho comunitario material), y una tercera parte que alberga dos contribuciones relativas a la posición de las Comunidades Autónomas españolas ante la reforma competencial europea, ya que las demandas de las entidades regionales se encuentran en el origen de este debate competencial. El libro se completa con la publicación de alguna de las comunicaciones que se presentaron en el Seminario en el que tiene su origen esta publicación, así como con varios anexos, de gran utilidad para enten- der el debate que se desarrolló en la Convención sobre estas cuestiones.

Como señala Diego J. Liñán en el prólogo, «la delimitación de competencias es el factor esencial de definición del modelo político y sobre él descansan todos los equilibrios de poder que lo sustentan». De ahí que la reforma de la delimitación competencial constituyese uno de los elementos más importantes del debate constitucional europeo, en la medida en que ponía las bases para la definición del futuro modelo político de la Unión. En ese marco, la oportunidad de esta obra colectiva resulta especialmente destacable.

La primera parte de esta publicación, con el título «cuestiones generales», contiene tres trabajos que estudian el sistema competencial desde una perspectiva global. El primero de ellos está firmado por el prestigioso profesor francés V. Constantinesco. Desde la perspectiva cada vez más federalista que preside sus últimas contribuciones, este profesor analiza la noción de soberanía, estudia el papel de las Constituciones en los Estados federales, y revisa el concepto de organización internacional. En ese contexto, el profesor Constantinesco reivindica una mayor relevancia y «un manejo más delicado» del principio de subsidiariedad, que en su opinión debería utilizarse incluso en «la asignación de las competencias comunitarias». El segundo trabajo de la primera parte es obra de J. Díez-Hochleitner, que nos ofrece un extenso y detallado estudio del sistema competencial actualmente vigente, para proceder con posterioridad a un análisis comparativo de las dispo- 
siciones del proyecto de tratado constitucional (PTC). Si tenemos en cuenta la calidad del autor, y que se trata de uno de los primeros trabajos publicados sobre el tratamiento de esta cuestión en el PTC, es fácil anticipar que nos encontramos ante uno de esos estudios que condicionan el debate doctrinal desde su publicación. El espíritu crítico del Prof. Díez-Hochleitner le lleva a censurar la clasificación competencial del PTC, que no considera suficientemente esclarecedora, y le permite detectar algunos errores que en su opinión se han cometido en la identificación como exclusivas, compartidas o complementarias (ahora rebautizadas como de apoyo, coordinación y complemento) de algunas competencias. El tercer trabajo es obra de J. Martín y Pérez de Nanclares, uno de los pocos autores españoles habitualmente citados por la doctrina alemana, que es la que más ha trabajado la problemática competencial en el ámbito europeo. El estudio aborda el papel de la flexibilidad, entendida en sentido amplio (cooperación reforzada, abstención constructiva, regímenes jurídicos diferenciados y modelo de Schengen), como instrumento básico del futuro modelo competencial europeo.

La segunda parte del libro se centra en el estudio de la delimitación competencial en tres ámbitos materiales, en los que el reparto de competencias entre la Unión y sus Estados miembros resulta especialmente problemático y complejo. El profesor J. Roldán aborda el siempre polémico ámbito de las relaciones exteriores, donde, como él señala, las necesidades impuestas por la realidad, y en especial el estatismo propio del medio internacional, así como la resistencia de los propios Estados miembros de la Unión, impiden a ésta asumir plenamente sus competencias exteriores. Siempre con el manejo de los datos y la jurisprudencia más recientes, J. Roldán repasa los principales problemas existentes en este terreno, desde una perspectiva multilateralista y desde una apuesta por la potenciación de las competencias exteriores europeas. Por su parte, M. López Escudero se adentra en el complicado mundo de la delimitación competencial de la vertiente exterior de la UEM, distorsionada por la asimetría entre las competencias comunitarias "económicas" y "monetarias", así como por la no participación de todos los Estados miembros en el euro. En este trabajo, López Escudero estudia, inter alia, las competencias de la CE para la celebración de tratados internacionales sobre la base del art. 111 TCE, las fórmulas utilizadas para su participación y representación en organizaciones $\mathrm{y}$ foros internacionales, y las escasísimas novedades que en este tema aporta el PTC, para terminar señalando a los Estados miembros como los principales responsables de una situación insatisfactoria. A. del Valle Gálvez aborda en su trabajo el estudio de la delimitación de competencias en el espacio de libertad, seguridad y justicia. Para ello, primero examina la naturaleza y los contenidos materiales de dicho espacio, analizando posteriormente las modificaciones introducidas por el PTC. En relación con esto último, el Prof. del Valle valora positivamente las nuevas lógicas sistemáticas de conjunto y por secciones del PTC, así como la comunitarización material de este ámbito.

El libro se completa con una tercera parte, dedicada a la posición de las Comunidades Autónomas ante la reforma competencial, en la que aparecen dos trabajos. A. Mangas, tras pasar revista al marco jurídico europeo, realiza 
un estudio particularmente "nacional», revisando la estrategia de las Comunidades Autónomas (CCAA) españolas para adquirir mayor representatividad y capacidad de influencia en la actividad comunitaria. En especial, esta Profra. analiza con su habitual rigor las distintas posibilidades de representación directa de las CCAA en el ámbito comunitario, y se muestra muy crítica con las posiciones de los anteriores gobiernos españoles, así como con las posturas del nacionalismo independentista, en un contexto en el que ella defiende una fórmula prudente de participación autonómica en el Consejo. La réplica a este trabajo la da J. M. Pérez Medina, que estudia la misma cuestión desde la atalaya privilegiada que le ha proporciona- do su experiencia como Coordinador del Área de Asuntos Europeos en el Ministerio de Administraciones Públicas. La obra colectiva termina con una Comunicación de la Profra. T. Fajardo sobre el papel de las Declaraciones anexas a las actas del Consejo en el proceso de delimitación de competencias.

En definitiva, un libro excelente, fruto de la pluma de varios de los mejores especialistas en derecho comunitario de nuestro país, y consecuencia de un Seminario en el que la calidad de los participantes generó un clima de alto nivel en los debates, poco habitual en los tiempos que corren.

L. M. Hinojosa, U. Granada

SEgura SerRano, A.: El interés general y el comercio de servicios, Tecnos, Madrid, 2003, 239 pp.

En un contexto histórico como el actual, dominado por la globalización y sus efectos sobre múltiples ámbitos, las relaciones comerciales internacionales han sido objeto de profundas transformaciones que han conducido a una apertura cada vez mayor de los mercados mundiales de bienes y servicios. Como manifiesta el autor de esta obra, la existencia de un comercio no restringido «puede originar problemas de orden social» (p. 17), lo que hace necesario un tratamiento adecuado en el marco del Ordenamiento internacional, y en el comunitario, de la protección del conjunto de todos aquellos valores sociales que se podrían encuadrar en el concepto de interés general.

De esta premisa parte el Dr. Segura Serrano para analizar la protección del interés general en el comercio de servicios en esta completa y rigurosa monografía que constituye la versión actualizada y abreviada de su tesis doctoral, defendida en abril de 2001 en la Universidad de Granada.

En opinión de dicho autor, «el interés general se ha configurado en el plano internacional como la noción que sirve de contrapeso al objetivo del libre comercio» de tal manera que se convierte en «el concepto clave que permite determinar el alcance de la libertad de comercio regulada en el marco de la OMC y en el seno de la Comunidad Europea» (p. 18).

En atención a ello estructura su trabajo en dos partes en las que estudia de manera comparada el interés general en el Acuerdo General sobre el Co- 
mercio de Servicios (GATS) y en el marco de la libre prestación de servicios dentro de la Comunidad Europea.

No obstante, con el objeto de conseguir una definición operativa del concepto de interés general, tiene que proceder con carácter previo al estudio del interés general como noción jurídica en el Capítulo I, en el que realiza en primer lugar un análisis político-ideológico del interés general para concluir posteriormente con un análisis jurídico del mismo, tanto desde la perspectiva normativa o legal de aquel, como de su control judicial.

La Primera Parte comprende los Capítulos II y III. Concretamente el Capítulo II lo dedica al estudio de la protección del interés general por vía de excepción en el GATS, procediendo a un análisis detallado de su artículo XIV y de los distintos motivos de interés general recogidos en el mismo, para finalizar con un breve comentario sobre la evolución jurisprudencial seguida en el marco de las excepciones generales, particularmente en virtud de determinados pronunciamientos que ha elaborado el Órgano de Apelación de la OMC sobre el apartado $g$ ) del artículo XX del GATT que, como el mismo autor destaca, han marcado un cambio de política jurisprudencial que afecta a la interpretación y aplicación de las excepciones generales.

La acción institucional que se puede desarrollar en beneficio de la protección del interés general en el marco del GATS es objeto de estudio en el Capítulo III, en el que se analizan distintas técnicas jurídicas que conjugan la liberalización comercial con la protección del interés general tales como el least trade-distorting regulation principle, el reconocimiento mutuo o la armoniza- ción, y que, a juicio del autor, constituyen las vías ineludibles para profundizar en la liberalización del comercio de servicios sin que ello traiga consigo la desprotección del interés general, aunque a su vez reconozca que son técnicas que hasta el momento no han tenido una incidencia práctica reseñable.

Los tres últimos capítulos de esta monografía quedan comprendidos en la Segunda Parte de la misma. Como ya lo haría en el Capítulo II con respecto al GATS, consagra el Capítulo IV al estudio de la protección del interés general por vía de excepción en la libre prestación de servicios dentro de la Comunidad Europea. De esta manera se analizan las cláusulas del ejercicio del poder público y la de orden público, seguridad y salud públicas recogidas en los artículos 45 y 46 del TCE.

El Capítulo V lo dedica al análisis de la doctrina de las razones imperiosas ligadas al interés general y las condiciones de aplicabilidad de la misma a través del estudio detallado de la crucial jurisprudencia del Tribunal de Justicia de las Comunidades Europeas en este ámbito.

Por último, en el Capítulo VI se procede al examen de la actuación positiva desarrollada en la Comunidad Europea en beneficio de la protección del interés general en el marco de la libre prestación de servicios, del que extrae la posibilidad de que el interés general pase de ser una doctrina judicial a convertirse en un concepto normativo.

Nos encontramos, en fin, con un excelente trabajo en el que se exponen las carencias con las que todavía cuenta la protección del interés general tanto en el comercio internacional de servicios como, aunque en menor medida, en el marco de la libre prestación de servi- 
cios dentro de la Comunidad Europea. Carencias de las que hallamos una clara muestra en el hecho de que la responsabilidad última de dicha protección siga recayendo en el Estado, como se- ñala el Dr. Segura Serrano en las conclusiones con las que finaliza su obra.

M. Á. Cepillo, U. Cádiz

VV.AA., New Directions in European Public Law, editado por J. Beatson; T. Tridimas, Harty Publishing, Oxford, 1999, 191 pp.

Al margen del mecanismo de armonización legislativa previsto por los arts. 94 y 95 TCE existe un proceso cultural más sutil y difícil de descifrar que es el objeto de estudio de la presente obra reseñada: la llamada crossfertilisation. Se trata de un fenómeno jurídico muy debatido y analizado en la doctrina legal europea y que hunde sus raíces en un mecanismo cultural de absorción del paradigma comunitario. En esta recopilación de ensayos destaca esta profunda capacidad del Derecho comunitario de incidir en la construcción interna de figuras legales mediante la llamada «fuerza gentil» (T. PADOA SCHIOPPA, Europa, forza gentile, Il Mulino, 2001). Es, sin duda, un campo de análisis complejo cuya latitud y longitud desborda los límites trazados por el normativismo puro de las directivas o reglamentos comunitarios y que merece una profunda y constante atención también en el escenario científico español.

Este libro centra su atención principalmente en el estudio del fenómeno de cross-fertilisation en el ámbito de la responsabilidad del Estado por vulneración del derecho comunitario. En la introducción firmada por Beatson y Tridimas, profesores de la Universidad de Cambridge, se arrojan las bases conceptuales del conjunto de la obra. ¿Qué sig- nifica cross-fertilization en el terreno jurídico? Se trata de adaptar un paradigma conceptual, como la responsabilidad del Estado, a la realidad jurídica interna de cada sistema estatal. No es un simple trasplante legal, donde el principio comunitario se adhiere tout court al terreno nacional. En la cross-fertilisation el estímulo externo se adapta a la realidad nacional, de manera que cada ordenamiento asimilará a su manera el impulso común. La profunda convergencia hacia un paradigma conceptual de responsabilidad no excluye, sin embargo, la existencia de diferentes ideas de Estado. "State liability depends on a concept of the State» (p. 10). La introducción, además, abre una ventana a la enorme capacidad de la que dispone el principio de responsabilidad de incidir en los estratos constitucional, administrativo y, obviamente, comunitario. En este último ámbito, se coloca el ensayo del prof. Tridimas, el cual comienza situando históricamente el principio de responsabilidad en la línea evolutiva de la jurisprudencia del Tribunal de Justicia de las Comunidades Europeas. Al mismo tiempo, el autor traza también los confines últimos de este principio asentándolos principalmente en la actividad del legislador nacional y en el requisito de la violación suficientemente caracterizada. En ambos elementos re- 
salta la «importance of national law» (título del párrafo en p. 27), o sea, la aportación del derecho estatal en la construcción del principio comunitario. Se perfila, por tanto, una dialéctica muy interesante entre las exigencias de primacía supranacional y la defensa de la autonomía estatal, confirmada a contraluz en toda la jurisprudencia del Tribunal de Justicia.

El punto de mayor interés del artículo del prof. Van Gerven consiste en la crítica a la remisión al art. 215 TCE operada en la sentencia Factortame III por parte del Tribunal comunitario. Aquí la cross-fertilisation es -por así decirlo- interna al ordenamiento comunitario. El intento de homologar en una única categoría general de responsabilidad supuestos tan variados y contrastantes provocaría a largo plazo una discriminación en la protección jurídica del ciudadano afectado. Los trabajos de los profesores Oliver y Eeckhout tratan de contextualizar el principio de responsabilidad del Estado en el conjunto comunitario de remedies previstos en defensa del ciudadano. Muy sugestiva es la contribución del prof. Craig, que se centra en las consecuencias internas de la jurisprudencia del Tribunal de Justicia sobre responsabilidad del Estado miembro. El autor distingue el impacto de este principio jurisprudencial en dos categorías según contengan perfiles exclusivamente comunitarios (es decir, de infracción del Derecho comunitario), o se coloquen al margen del cualquier disputa de tipo supranacional. El principio de responsabilidad comienza a aplicarse no sólo en los casos que afectan directamente a la violación de derechos comunitarios, sino que, más profundamente, extiende un efecto spillover en el conjun- to del sistema nacional de responsabilidad. Los efectos culturales de los principios comunitarios son la esencia más recóndita del proceso de integración. A este propósito, Mark Hoskins esboza un escenario de las posibles respuestas del sistema inglés al paradigma comunitario de responsabilidad estatal, llegando a la conclusión de que ha de recurrirse a una nueva figura extracontractual: the innominate tort. Analiza el mismo proceso conceptual en el ámbito jurídico italiano Luisa Torchia, concluyendo que se está abriendo camino una nueva sintaxis comunitaria, cuya característica esencial es la persistente dialéctica entre los sistemas nacionales y comunitario.

Eivind Smith se detiene en el estudio de la cross-fertilisation a nivel constitucional (muy emblemático es el título del ensayo de Smith: «Give and Takes: Cross-fertilisation of Concepts in Constitucional Law»). Perfilada la noción de cross-fertilisation constitucional, el autor trata de investigar las repercusiones y arreglos internos relativos a los principios de soberanía parlamentaria, de jerarquía de las fuentes del derecho y de protección de los derechos. Es indudable que la aplicación del principio de responsabilidad comunitario conlleva un reajuste del entramado conceptual del Derecho constitucional interno, que sustancialmente termina por desplazar el peso constitucional de su aplicación hacia las decisiones judiciales, asunto profundizado con notable agudeza en el trabajo de Ivan Hare.

Particular atención merecen los últimos tres trabajos de esta recopilación. En el capítulo $12 \mathrm{~J}$. Allison explica la diferencia sustancial entre el fenómeno de transplante legal y el proceso más complejo de cross-fertilisation, dedican- 
do amplia atención al factor diferenciador del análisis cultural del Derecho. En el último capítulo Tridimas se encarga de resumir la larga y compleja jurisprudencia del Tribunal de Justicia acerca de la responsabilidad del Estado miembro por vulneración del derecho comunitario, remarcando la importancia del diálogo institucional y cultural entre los jueces nacionales y el juez comunitario.

Finalmente el Prof. Bell dibuja un fresco fascinante del funcionamiento de la cross-fertilisation en el campo administrativo. Siempre al hilo del equilibrio entre la preservación de la cultura estatal y los nuevos desarrollos comuni- tarios, Bell afirma paradigmáticamente que la cross-fertilisation implica la adaptación del estímulo externo al humus cultural nacional, de manera que cada sistema asimilará y producirá un principio propio de responsabilidad de origen comunitario. Se fundirán en un novel Aufhebung hegeliano lo nuevocomunitario y lo antiguo-tradición cultural estatal. El estudio de la mentalidad nacional no excluye una clara convergencia de los sistemas nacionales de responsabilidad en la dirección fijada por el paradigma comunitario.

A. Lazari, U.P. Olavide

VV.AA., Convergence and Divergence in European Public Law, editado por P. Beaumont; C. Lyons; N. Walker, Hart Publishing, Oxford, 2002, 271 pp.

El objeto de este estudio es igualmente, como en la recensión anterior, la llamada cross-fertilisation.

Curiosamente compuesto también por trece ensayos, esta obra se divide temáticamente en cinco partes. En la primera, Michael Keating e Joanne Scout debaten la dimensión territorial del proyecto comunitario, evidenciando ambos la tríplice configuración espacial de la nueva Europa: local o regional, estatal y supranacional. A esta nueva ordenación han de corresponder nuevos métodos de articulación cultural, funcional y constitucional. La dimensión constitucional del proceso de integración ocupa la segunda parte. Con admirable sagacidad, De Witte apunta que los destinos de Europa dependen esencialmente de un proceso de «conversación» judicial y constitucional. La primera se sustancia en la relación dialéc- tica entre tribunales nacionales y comunitario que condiciona, y la vez, está condicionada por la segunda, que ve como protagonistas los Estados miembros, principalmente en las Conferencias Intergubernamentales.

Al dilema inicial entre la tendencia convergente o divergente arroja luz Carole Lyons, la cual, aun reconociendo la persistencia de arraigadas y profundas mentalidades nacionales, no llega a la conclusión de que éstas sean impermeables a cualquier infiltración comunitaria. «The process of convergence is just as amorphous in its many manifestations as national legal cultures can be» (p. 48). Se trata una vez más de un fenómeno poco receptivo a las herramientas del normativismo y que se explica sólo teniendo en debida cuenta factores como las culturas estatales, las tradiciones constitucionales, etc. La 
existencia de diferentes culturas nacionales - subraya Lyons- facilita, no impide, la libre circulación de modelos comunitarios. En la tercera sección del libro se aborda la cuestión de la divergencia-convergencia en relación al aspecto administrativo. El breve ensayo de Himsworth nos recuerda que el proceso de convergencia jurídica es extremadamente delicado en tanto que se refiere sólo a algunas actividades socioeconómicas y depende de la sensibilidad legal de los jueces. Todo ello se traduce sustancialmente en una evidente situación de desigualdad entre ciudadanos europeos. Ferviente atención suscita la tesis de Heunkels y Tib, que desentrañan la esencia de las tendencias a la convergencia y divergencia jurídica europea. Su radio de acción se limita al estudio de los medios de tutela judicial, donde los autores hallan dos corrientes históricas de hondo calado político: la primera se resume en el test-Rewe y la segunda se aglutina alrededor de la sentencia Francovich. Una vez más el tema de la responsabilidad del Estado sirve para trazar un surco entre la fase minimalista del proceso de integración europea, en la que dominaba el principio de autonomía procesal y, a lo sumo, los intereses de los gobiernos estatales; y una segunda, caracterizada por la sentencia Francovich donde se impone un proceso de comunitarización a breve y largo plazo. En este último supuesto se coloca el mecanismo de convergencia europea mediante el fenómeno ya visto en el comentario anterior, de cross-fertilisation. Meritorios son los trabajos de la cuarta parte acerca del proceso de convergencia europea en los derechos humanos, sin embargo, merece una particular atención la quinta y última sec- ción dedicada a la dimensión pública y privada del mecanismo de convergencia cultural. El fulcro de la recopilación rueda alrededor de los ensayos de Harlow y Legrand sobre la defensa de las culturas jurídicas nacionales: el primero en la esfera democrática, el segundo en aquella más estrictamente cultural. La tesis defendida por Harlow es que a nivel cultural («Law as culture») y democrático («Law and Democracy») el proceso de integración europeo puede entrar en conflicto y mermar seriamente las tradiciones nacionales (las mentalités en la expresión de Legrand). El fascinante y exhaustivo estudio acerca de la cultura legal termina por dogmatizar la mentalidad legal estatal, que no se ha visto erosionada por el Derecho comunitario: es una realidad más profunda que la superficie del derecho comunitario. Se pone en tela de juicio la propia razón de ser del Derecho comunitario vaciado de cualquier significado político y cultural y defiende a ultranza la democracia exclusivamente en los confines estatales. A las mismas conclusiones arriba desde diferentes presupuestos la sugestiva propuesta de Legrand, cuyo punto de partida es la noción de mentalité. El Derecho comunitario es simplemente un epifenómeno, es decir, un fenómeno legal que se queda sólo en la superficie sin hundir sus raíces en factores antropológicos, sociológicos, filosóficos, históricos y psicológicos. De hecho, la persistencia de una mentalidad más profunda explica también la emersión de áreas de resistencia contrarias a la aplicación del derecho comunitario. La cultura concierne factores valorables con regularidad sólo a largo plazo en la longue durée: representa un conjunto de creencias o predisposiciones propias de un determi- 
nado pueblo. Es la historia de ideas colectivas que se aglutinan en un contexto extra-verbal. También en la óptica de Legrand se pone en entredicho la herramienta-derecho (que representa sólo una expresión de esta identidad colectiva) y más aún el Derecho comunitario. Volviendo a la definición de crossfertilisation del primer libro, el autor se detiene más en el análisis de los fenómenos de resistencia al impulso comunitario que en el de su asimilación. Es un punto extremadamente interesante. Para Legrand la disyuntiva inicial se resuelve de esta forma: convergen los fenómenos superficiales, perseguidos artificialmente por una elite de burócratas (el Derecho comunitario); diverge la sustancia de la realidad cultural, económica y social. Menos radical es la postura de Neil Walker, el cual persigue la metodología de la legal culture, pero lúcidamente sostiene que las culturas estatales están destinadas a acercarse a cualquier nivel: legal, social y cultural. Contrario a los fundamentalismos de la convergencia o divergencia, el profesor del Instituto Europeo de Florencia evidencia el alcance de la interacción entre sistemas jurídicos aún más en el marco del derecho supranacional europeo.

Un sutil file rouge atraviesa y une las obras del primer y segundo libro: la búsqueda de nuevos métodos ajenos al positivismo europeo aplicados en el ámbito del Derecho comunitario. Ya sólo por este esfuerzo este tour d'horizon del panorama europeo suscita una atracción casi inmediata incluso en lectores no especialistas en Derecho comunitario.

\section{A. Lazari}

VV.AA., La ampliación europea: desafíos y oportunidades, Federación de Cajas de Ahorros Vasco-Navarras, Vitoria, 2003, 258 pp.

La reciente ampliación de la Unión Europea representa, a todas luces, unos de los procesos más impactantes en la reciente construcción europea. En efecto, las implicaciones jurídico-económicas en el contexto de los Estados miembros y de la propia Unión Europea, dan muestra de la complejidad de este proceso, pudiendo ser observado desde múltiples perspectivas. Es por todo ello que la labor desarrollada por la Federación de Cajas de Ahorros Vasco-Navarras y la Universidad del País Vasco en el estudio de las cuestiones más trascendentales de la ampliación debe ser valorada en su justa medida, implicando, además, un magnífico esfuerzo de simplificación y profundización para los interesados en la materia.

El volumen comentado en estas líneas, de cuidada presentación, recoge las distintas ponencias presentadas en los XXI Cursos de Verano y XIV Cursos Europeos, organizados por la Universidad del País Vasco durante el año 2003 y bajo la rúbrica «La ampliación de la Unión Europea: desafíos y perspectivas». El propio título recoge la esencia misma del contenido de la obra, en cuanto se procede al análisis de aquellas cuestiones que representarán un desafio no solamente para Europa sino más particularmente para 
España y el País Vasco, y las perspectivas de futuro una vez que nos encontramos en una Europa a 25. En definitiva, la obra realiza una evaluación de la situación partiendo desde un punto de vista jurídico hasta ir desengranando su análisis hasta llegar a un plano totalmente económico.

El volumen viene estructurado en cuatro Capítulos, a los que se añade un Anexo y un CD-Rom con material de apoyo y una extensa documentación para facilitar la comprensión de los ámbitos tratados. El primer Capítulo recoge las ponencias relativas a las distintas problemáticas institucionales, haciendo especial mención a los trabajos llevados a cabo en el seno de la Convención Europea (A. del Valle Gálvez). De este modo, se resalta la dificultad para alcanzar un consenso en cuanto a la composición de las distintas instituciones (Jean-Victor Louis), la complejidad que representa la identificación de las nuevas fronteras exteriores de la Unión Europea, y el impacto en las relaciones con terceros Estados tomando como base la política comercial comunitaria (M. López Escudero).

El segundo Capítulo se centra en la evolución de la cohesión económica y social de la Europa a 25 (A. García Herrero), puesto que, una vez llevada a cabo la ampliación, nos vamos a encontrar con regiones con un PIB muy por debajo de la media europea. Ello conllevará, inevitablemente, la alteración de los destinatarios de los fondos estructurales y de cohesión, con el consiguiente impacto en la propia estructura socio-económica española (M. A.
Moltó Calvo). Este segundo Capítulo estaría complementado con el tercer Capítulo de esta obra, el cual recoge las ponencias referidas a las consecuencias económicas de la ampliación y su impacto en España y el País Vasco, incluyéndose la opinión de diversos sectores regionales vascos.

Finalmente, el cuarto Capítulo, y desde un punto de vista exclusivamente económico, se inicia con una visión de la ampliación desde el Banco Central Europeo (E. Domingo Solans), desglosándose, a continuación, los estudios relativos al impacto que sobre el sector monetario y financiero (R. Echevarría Soto) y sobre los flujos de inversión extranjera directa (F. J. Velázquez Angona) conllevará este proceso de expansión. Todo el conjunto de Capítulos se encuentra completado con un anexo final en el cual se recoge las opiniones sobre la ampliación de representantes de Hungría y la República de Chequia, abarcando, de este modo, a todos los agentes implicados en el proceso de integración europeo.

En definitiva, debemos calificar de muy loable la decisión de la Universidad del País Vasco y de la Federación de Cajas de Ahorros Vasco-Navarras en dedicar sus Cursos de Verano correspondientes al año 2003 al proceso de ampliación europea. Sin duda alguna, el presente volumen constituye una útil herramienta para conocer las implicaciones más sobresalientes referidas a este proceso de expansión unificadora de todo el continente europeo.

M. A. Acosta 
BIBLIOGRAFIA

VV.AA.: Europa ante su futuro. Una visión desde Euskadi, Bilbao, Consejo Vasco del Movimiento Europeo, 2004, 234 pp.

Desde su creación como Comunidad Europea del Carbón y del Acero hasta la actualidad, marcada por un documento fundamental, El Proyecto de Tratado por el que se instituye una Constitución para Europa, las instituciones comunitarias han vivido en un estado de evolución constante. Hoy día, estamos en una etapa crucial para la Unión Europea, que vive uno de sus momentos más importantes desde que diera sus primeros pasos en los años cincuenta del siglo pasado. Momento importante que viene dado por diversos factores: en primer lugar, el proyecto de Constitución Europea, aunque se discutan su alcance y esencia (en esta misma obra que reseñamos se hace); en segundo lugar, la ampliación de la Unión hacia los antiguos países del bloque comunista; y, finalmente, aunque no menos importante, los cambios que se están produciendo en la configuración de la Sociedad Internacional, ante los que la Unión Europea tendrá que responder.

Teniendo en cuenta esta coyuntura de cambio, y ante una entidad en constante transformación como lo es la Europa Comunitaria, no es de extrañar que se publiquen obras que demuestren preocupación por el futuro de Europa. $Y$ es entre estas obras en dónde hay que situar la que aquí reseñamos. En esta ocasión se ha recurrido a la multidisciplinariedad, recurriendo tanto a especialistas en diversas ramas de Derecho (Internacional Público, Internacional Privado, Constitucional) y a políticos implicados en cuestiones relativas a Europa, como a representantes de la sociedad civil; multidisciplinariedad que enriquece el debate.
En esta obra se recogen las ponencias de un Seminario, del mismo título, celebrado en Bilbao el 27 de diciembre de 2003. Este Seminario, a tenor de lo expuesto en la presentación de José María González Zorrilla (Presidente del Consejo Vasco del Movimiento Europeo), en las conferencias de salutación (José María Urkia Etxabe, Director de la Real Sociedad Bascongada de Amigos del País, y José María Iruarrizaga, Diputado Foral de Hacienda de Bizkaia), y en la de apertura (Idoia Zenarruzabeitia, Vicelehendakari y Consejera de Hacienda y Administración Pública del Gobierno Vasco), pretendía ser una reflexión sobre el proyecto de Constitución Europea, sobre todo en lo que a las cuestiones regionales se refiere, pensando, en principio, en el público vasco, y partiendo de las carencias del proyecto constitucional en lo que a las regiones se refiere.

Las obra va más allá de los objetivos fijados por los organizadores del Seminario, si tenemos en cuenta la temática de las ponencias expuestas.

Por supuesto, se debate sobre el papel que la nueva constitución concede a las llamadas Reg-Leg (regiones con competencias legislativas), bien realizando una valoración negativa (la ponencia de Mikel Antón Zarragoitia, Director para Asuntos Europeos del gobierno Vasco), bien no concediéndole mayor importancia a la cuestión (como hace José María Gil-Robles).

También tenemos ponencias sobre otros aspectos del proyecto constitucional. Partiendo de las de ámbito más general, tenemos dos excelentes valoraciones críticas (las de Paz Andrés 
Sáenz de Santa María, catedrática de Derecho Internacional Público de la Universidad de Oviedo y la de Miguel Martínez Cuadrado, catedrático de Derecho Constitucional de la Universidad Complutense) sobre el proyecto de Constitución, que incluyen además amplia información sobre su proceso de elaboración. Estas dos ponencias se complementan con otras sobre ámbitos más concretos del proyecto constitucional: la del profesor Francisco Javier Quel López, catedrático de Derecho Internacional Público, sobre la PESC; la del catedrático de Derecho Internacional Privado de la Universidad Complutense, José Carlos Fernández Rozas, sobre el espacio de libertad, seguridad y justicia; finalmente, las que versan sobre temas de ciudadanía: Juan José Álvarez Rubio (del Consejo Vasco del Movimiento Europeo), Mitxel Unzueta (de la Real Sociedad Bascongada de Amigos del País y abogado), Joxerramon Bengoetxea, (letrado del TJCE). Estas reflexiones sobre el futuro texto constitucional, se completan con una ponencia sobre la ampliación de la Unión Europea vista desde Polonia, a cargo de Bartolomiej Swiderek, asesor sobre Ampliación en el Grupo Verdes/ Alianza Libre Europea del Parlamento Europeo. Todo ello complementado con un análisis final del seminario a cargo de José Martín y Pérez de Nanclares, catedrático de Derecho Internacional Público de la Universidad de La Rioja.

La calidad de todas las ponencias es elevada: bien sea por sus aportaciones científicas o por la aportación de la ex- periencia personal de algunos de los ponentes acerca del tema del que se ocupan. En el caso de las primeras, se ha huido del resumen fácil, con valoraciones personales y reflexiones para el debate, todo ello profusamente documentado. En el caso de la experiencia personal, su valor resulta más que evidente, pues completa e ilustra a la perfección las valoraciones realizadas desde el punto de vista académico, ofreciendo además, nuevas líneas de debate. Por otra parte, y en general, no se ha caído en el halago, planteando cada ponente tanto aspectos negativos como positivos.

De este modo, la obra no sólo cumple con los objetivos planteados por los organizadores del seminario, sino que los supera con creces, pues, aunque la obra plantee, como reza en el título «Una visión desde Euskadi» va más allá no sólo de la perspectiva de Euskadi, sino que, a tenor de la temática de las ponencias, incluso aquellas que tratan de cuestiones relativas a las regiones, contiene reflexiones de conjunto sobre las perspectivas de futuro de la Unión Europea, válidas para cualquier otra región europea de las mismas características.

Nos encontramos por tanto ante una obra de gran valor para el lector interesado no sólo en temas de Derecho Comunitario, sino en temas europeos en general. Una obra que contribuye a fomentar la reflexión y el debate sobre el futuro de Europa.

\section{J. D. Torrejón, U: Cádiz}


ANUNCIOS 


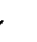




\section{Revista de Administración Pública}

Director: EduARDo Garcia de ENTERRÍA

Secretaria: CARmen Chinchilla Marín

Números 1 - 162

Años 1950-2003

presentados en

DVD-ROM y CD-ROM

PRECIOS VENTA AL PÚBLICO

\begin{tabular}{|c|c|}
\hline SUSCRIPTORES & NO SUSCRIPTORES \\
\hline DVD-ROM: 200 $€$ & DVD-ROM: 250 $€$ \\
CD-ROM: 200 $€$ & CD-ROM: 250 $€$ \\
\hline
\end{tabular}

Venta directa y pedidos por correo

CENTRO DE ESTUDIOS POLÍTICOS Y CONSTITUCIONALES

San Francisco de Sales, 6 - 28071 MADRID

Tel. (34) 914412700 - Fax (34) 914410086 E-mail: distribrev@cepc.es 


\section{Revista de Administración Pública}

Director: EdUARDo GARCÍA DE ENTERRÍA

Secretaria: CARMEN CHINCHILla MARÍN

Sumario del núm. 163 (Enero-Abril 2004)

\section{ESTUDIOS}

A. EMBID IRUJO: El soterramiento de las líneas eléctricas. problemática jurídica general.

S. GONZÁLEZ-VARAS IBÁNEZ: Hacia un modelo contencioso-administrativo preventivo. El ejemplo de la «ejecución» de las sentencias anulatorias de un plan urbanístico.

C. Cierzo Selra: El principio de precaución: reflexiones sobre su contenido y alcance en los Derechos comunitario y español.

M. ' Y. Fernández García: Las obligaciones especiales de los operadores de los servicios esenciales económicos en red.

\section{JURISPRUDENCIA}

I. Comentarios monográficos:

E. García-Trevijano GaRnica: ¿Existe plazo para recurrir contra desestimaciones por silencio administrativo negativo?

E. Garcia de Enterrfa: La Sentencia del Tribunal Europeo de Derechos Humanos de 28 de octubre de 2003, Stone Court Shipping Company, S.A. c/España, y las prácticas judiciales españolas para inadmitir recursos.

II. Notas de Jurisprudencia Contencioso-Administrativa.

\section{CRÓNICA ADMINISTRATIVA}

I. Española y comunitaria:

S. MUÑoz MACHADO: Los protagonistas de la cultura juridica europea: un homenaje a la obra de Eduardo García de Enterría.

A. NOGUEIRA LÓPEZ: El nuevo marco competencial del profesorado universitario.

J. ORTIZ MALlol: La relación de dependencia de las entidades instrumentales de la Ad. ministración Pública: algunas notas.

A. J. SÁNCHEZ SÁEZ: Los acuerdos voluntarios para la protección del medio ambiente. SEGLERS: La inscripción registral de las confesiones religiosas: analisis de los requisitos legales.

B. SETUÁIN MENdía: Aspectos normativos de los mercados de aguas: últimas aportaciones desde la reforma del Reglamento del Dominio Público Hidráulico.

II. Extranjera:

M. Almeida Cerreda: Los convenios interadministrativos en el Derecho italiano.

G. ARENA: E-government y nuevos modelos de administración.

S. FERnÁndez RAmos: La transparencia administrativa en Portugal. Una referencia para el Derecho Administrativo español.

F. L. HERNÁNDEZ GONZÁlEZ: La evolución de la potestad reglamentaria en el constitucionalismo francés. Mitos y realidades.

E. M. ${ }^{\mathbf{a}}$ MenÉndez SEbASTÍN: El reenvio como técnica de fraude del sistema postal internacional y del servicio universal.

DOCUMENTOS Y DICTÁMENES. BIBLIOGRAFÍA

PRECIOS AÑO 2004

\begin{tabular}{|c|c|c|c|}
\hline \multicolumn{2}{|c|}{ NÚMERO SUELTO } & \multicolumn{2}{|c|}{ SUSCRIPCIÓN ANUAL } \\
\hline España & Extranjero & España & Extranjero \\
\hline $18,00 €$ & $25,00 €$ & $51,00 €$ & $74,00 €$ \\
\hline Números 1-162 & $\begin{array}{r}0-2003), \mathrm{pr} \\
250 €\end{array}$ & $\begin{array}{l}\text { n DVD-RO } \\
\text { s } 200 €\end{array}$ & $y$ en $C D$ \\
\hline
\end{tabular}

Suscripciones, venta directa y pedidos por correo de números sueltos:

CENTRO DE ESTUDIOS POLÍTICOS Y CONSTITUCIONALES

San Francisco de Sales, 6 - 28071 MADRID

Tel. (34) 914412700 - Fax (34) 914410086 E-mail: distribrev@cepc.es 


\section{Revista de Estudios Políticos}

(NUEVA ÉPOCA)

Director: Pedro de Vega García

Secretario: JuAN J. SolozÁbal EchaVARRía

Núm. 123 (Enero-Marzo 2004)

\section{ESTUDIOS}

ARmin Von Bogdandy, JÜRge Bast, Félix ARndT: Tipología de los actos en el Derecho de la Unión Europea. Análisis empírico y estructuras dogmáticas en una presunta jungla.

Miguel Beltrán Villalva: Liberalismo y burguesía en la menor edad de Isabel II: una mirada sociológica a la España postfernandina.

Bartolome Clavero: ¿Qué historia, para qué Constitución, de qué Europa?

RAMÓN MÁIZ: El indigenismo político en América Latina.

MANUEl ÁlVAREZ TARDío: Ni República parlamentaria ni presidencialista.

\section{NOTAS}

José Vilas Nogueira y Manuel Ángel Fernández Baz: El BNG: definición y evolución de su estructura organizativa.

MONTSERRAT NeBRERA: «Patriotismo» y mutación constitucionales (En torno a la LO 6/ 2002 de partidos políticos y la STC 48/2003).

Germán Gómez ORFANEL: Soldados y ciudadanos, según Carl Schmitt.

JoAQUín BRAGE CAMAZANO: Algunos aspectos de teoría general constitucional sobre los derechos fundamentales en los EE.UU.

ENRIQUE GaRCÍA VIÑUela: Un modelo de participación electoral para las elecciones generales españolas (1993-2000).

JAVIER TAJADURA TEJADA: ¿El caso de Westfalia? Reflexiones en torno a la crisis del constitucionalismo en el contexto de la mundialización.

JuAN JosÉ RuIz RuIZ: «Antisenatica» en el trienio liberal (1820-23): Bentham contra la introducción del bicameralismo en España.

ANA GeNTEA: Hacia la humanización de la justicia penal en la Francia ilustrada: la aportación de Voltaire.

\section{RECENSIONES}

PRECIOS AÑO 2004

\begin{tabular}{|cc|cc|}
\hline \multicolumn{2}{|c|}{ NÚMERO SUELTO } & \multicolumn{2}{c|}{ SUSCRIPCIÓN ANUAL } \\
España & Extranjero & España & Extranjero \\
\hline $14,00 €$ & $20,00 €$ & $51,00 €$ & $74,00 €$ \\
\hline
\end{tabular}

Suscripciones, venta directa y pedidos por correo de números sueltos:

CENTRO DE ESTUDIOS POLÍTICOS Y CONSTITUCIONALES

San Francisco de Sales, 6 - 28071 MADRID

Tel. (34) 914412700 - Fax (34) 914410086 E-mail: distribrev@cepc.es 


\section{Revista de Estudios Polítleos}

(NUEVA ÉPOCA)

Director: Pedro de Vega García

Secretario: Juan J. Solozábal Echavarría

Núm. 124 (Abril-Junio 2004)

\section{ESTUDIOS}

JuAN José SolozÁbal EchaVARRIA: El Estado autonómico en perspectiva.

Francisco Fernández SEgado: La libertad de imprenta en las Cortes de Cádiz.

Manuel Alcántara SÁEZ: Partidos políticos en América Latina: precisiones conceptuales, estado actual y retos futuros.

MANUEl SÁNCHEZ DE DIOS: Estudio comparado de path dependence del Estado de bienestar en los casos de USA, Suecia y España.

TOMMASO EDOARDO FROSINI: Nuevas tecnologias y constitucionalismo.

JOAQUín ARTÉs CASELLES y ANTONIO BUSTOS GISBERT: Eficacia económica de la colaboración parlamentaria de CiU con el gobierno central en la $V$ y VI legislaturas.

DANIEL BERZOSA LÓPEZ: Los fisiócratas y la opinión pública como presupuesto y garantía de la continuidad de la sociedad en el Estado.

NOTAS

Pedro Fernández Barbadillo: El concierto económico vasco, ¿pacto entre iguales $o$ concesión?

José Antonio Rivas Leone y José Araque Calderón: Aventuras y desventuras del popularismo latinoamericano.

EdUARD TARNAWSKI: El capitalismo como poder, la política como negocio. Las lecciones de Thorstein B. Veblen sobre la transición rusa.

EVA SÁENZ RoYo: Prestaciones no contributivas y Comunidades Autónomas. Un comentario crítico a la STC 239/2002, de 11 de diciembre.

Manuel Fernández del Hoyo: La decisión de la Corte Suprema del Estado de Massachussetts en el caso de Goodridge \& others v. Department of public health \& another.

\section{RECENSIONES}

PRECIOS AÑO 2004

\begin{tabular}{|cc|cc|}
\hline \multicolumn{2}{|c|}{ NÚMERO SUELTO } & \multicolumn{2}{c|}{ SUSCRIPCIÓN ANUAL } \\
España & Extranjero & España & Extranjero \\
\hline $14,00 €$ & $20,00 €$ & $51,00 €$ & $74,00 €$ \\
\hline
\end{tabular}

Suscripciones, venta directa y pedidos por correo de números sueltos:

CENTRO DE ESTUDIOS POLÍTICOS Y CONSTITUCIONALES

San Francisco de Sales, 6 - 28071 MADRID

Tel. (34) 914412700 -Fax (34) 914410086 E-mail: distribrev@cepc.es 


\section{Revista Espaíola de Derecho Constltuclonal}

Director: Francisco Rubio LloRente

Secretario: JuAn Luis Requejo Pagés

Sumario del Año 24, núm. 70 (Enero-Abril 2004)

MONOGRÁFICO XXV ANIVERSARIO DE LA CONSTITUCIÓN (II)

ESTUDIOS

MANUEl ARAgón ReYes: Veinticinco años de monarquía parlamentaria.

RAMón PUNSET: Razón e identidad del Senado.

LUIS LÓPEZ GUERRA: El Gobierno y su regulación: enfoques positivos y negativos.

JuAN LUIS REQUEJo PAGÉs: Las relaciones entre el Gobierno y las Cortes Generales.

FRANCESC DE CARRERAS SERRA: Los partidos en nuestra democracia de partidos.

JUAN José Solozábal ECHAVARRfA: La actuación efectiva del proceso electoral y sus posibilidades.

Francisco CaAmaño Domínguez: Autonomía local y Constitución.

FRANCISCO FERnÁNDEZ SEgado: El estatuto jurídico-constitucional de las Fuerzas Armadas y su desarrollo legislativo. Balance de un cuarto de siglo.

NOTAS

Marf́a VAlvidares: Breve aproximación a la Constitución de la República Eslovaca.

Manuel José Terol Becerra: Crónica Político-Constitucional del año 2003.

\section{JURISPRUDENCIA}

Actividad del Tribunal Constitucional: Relación de sentencias dictadas durante el tercer cuatrimestre de 2003 (Departamento de Derecho Constitucional de la Universidad Carlos III de Madrid).

Doctrina del Tribunal Constitucional durante el tercer cuatrimestre de 2003.

Estudios críticos:

M. Ángeles Martín Vida y Sven Müller-Grune: ¿Puede una maestra portar durante las clases en una escuela pública un pañuelo en la cabeza por motivos religiosos? (Comentario a la sentencia del Tribunal Constitucional Alemán de 24 de septiembre de 2003, caso Ludin).

Miguel Pérez-Moneo Agapito: Parámetros para enjuiciar la continuidad entre partidos ilegalizados y agrupaciones de electores. (La conexión entre las Sentencias del Tribunal Supremo de 3 de mayo de 2003 y là STC 85/2003).

\section{CRÍTICA DE LIBROS}

JOSÉ ESTEVE PARDo: Una conversación optimista sobre la democracia en las sociedades complejas.

Mónica ARENAS Ramiro: Autoridades independientes. Un análisis comparado de los Estados Unidos, el Reino Unido, Francia y España.

RESEÑA BIBLIOGRÁFICA

Noticias de Libros.

PRECIOS AÑO 2004

\begin{tabular}{|cc|cc|}
\hline \multicolumn{2}{|c|}{ NÚMERO SUELTO } & \multicolumn{2}{c|}{ SUSCRIPCIÓN ANUAL } \\
España & Extranjero & España & Extranjero \\
\hline $16,00 €$ & $23,00 €$ & $46,00 €$ & $67,00 €$ \\
\hline
\end{tabular}

Suscripciones, venta directa y pedidos por correo de números sueltos: CENTRO DE ESTUDIOS POLÍTICOS Y CONSTITUCIONALES

San Francisco de Sales, 6 - 28071 MADRID

Tel. (34) 914412700 - Fax (34) 914410086 E-mail: distribrev@cepc.es 


\section{Derecho Privado y Constitución}

Director: Rodrigo Bercovitz RodríGuez-CANO

Secretario: JuAN JosÉ MARín LÓPEZ

Sumario del núm. 17 (Año 2003)

NÚMERO MONOGRÁFICO SOBRE FUENTES DEL DERECHO

EN HOMENAJE AL PROFESOR JAVIER SALAS HERNÁ NDEZ

PRESENTACIÓN, por Elisenda MaLARET GarCia.

ESTUDIOS

COLABORAN:

Mariano Bacigalupo Sagesse, Germán José Marfa Barreiro GonZález, Rodrigo Bercovitz Rodríguez-Cano, María Emilia Casas baamonde, Pedro Cruz Villalón, Montserrat Cuchillo Foix, Jesús Delgado Echevarría, Tomás "Font i Llovet, Eduardo García de Enterría, Rafael Illescas, Jesús leguina Villa, Elisenda Malaret Garcia, Carlos J. Maluquer de Motes Bernet, lorenzo MartínRetortillo Baquer, Luis Ortega Álvarez, Juan Ramallo Massanet, Juan José Solozábal Echavarría, Joaquín Tornos Mas, Fernando Valdés Dal-Ré.

PRECIOS AÑO 2003

\begin{tabular}{|c|c|}
\hline \multicolumn{2}{|c|}{ NÚMERO SUELTO O SUSCRIPCIÓN ANUAL } \\
\hline España & Extranjero \\
\hline $15 €$ & $23 €$ \\
\hline
\end{tabular}

Suscripciones, venta directa y pedidos por correo de números sueltos:

CENTRO DE ESTUDIOS POLÍTICOS Y CONSTITUCIONALES

San Francisco de Sales, 6 - 28071 MADRID

Tel. (34) 914412700 - Fax (34) 914410086 E-mail: distribrev@cepc.es 


\section{Anuario Iberoamericano de Justicia Constitucional}

Director: Francisco Fernández Segado

Secretario: Raúl CANOSA USERA

Núm. 7 (Año 2003)

\section{ESTUDIOS DOCTRINALES}

COLABORAN:

Jorge Asbun, Giorgio Berti, Giovanni Blaggin, Paulo Bonavides, Jorge Carpizo, ivo Dantas, María angélica Gelli, Jorge Horacio Gentile, Peter Häberle, RiCardo Haro, Winfried Hassemer, Antonio M. ${ }^{a}$ Hernández, Friedric Müller, J. Jesús Orozco Henríquez, J. M. Othon Sidou, Jaceues Robert, Antonio Ruggeri, Fernando Saenger Gianoni, Herbert Schambeck, Christian Starck, Albrecht Weber, ARTuto Zaldivar Lelo de Larrea.

\section{ESTUDIOS JURISPRUDENCIALES}

COLABORAN:

JoRge Miranda, Jorge SEall-Sasiain.

COMENTARIOS BIBLIOGRÁFICOS

PRECIOS AÑO 2003

\begin{tabular}{|c|c|}
\hline \multicolumn{2}{|c|}{ NÚMERO SUELTO O SUSCRIPCIÓN ANUAL } \\
\hline España & Extranjero \\
\hline $24 €$ & $30 €$ \\
\hline
\end{tabular}

Suscripciones, venta directa y pedidos por correo de números sueltos: CENTRO DE ESTUDIOS POLÍTICOS Y CONSTITUCIONALES

San Francisco de Sales, 6 - 28071 MADRID

Tel. (34) 914412700 - Fax (34) 914410086 E-mail: distribrev@cepc.es 
REVISTA DE

Estudios Políticos

Publicación trimestral

REVISTA DE

Derecho Comunitario

Europeo

Publicación cuatrimestral

REVISTA DE

Administración Pública

Publicación cuatrimestral

REVISTA ESPAÑOLA DE

Derecho Constitucional

Publicación cuatrimestral

\section{Derecho Privado}

y Constitución

Publicación anual

ANUARIO IBEROAMERICANO DE Justicia Constitucional

Publicación anual

CENTRO DE ESTUDIOS POLÍTICOS Y CONSTITUCIONALES

Plaza de la Marina Española, 928071 Madrid. (España) 


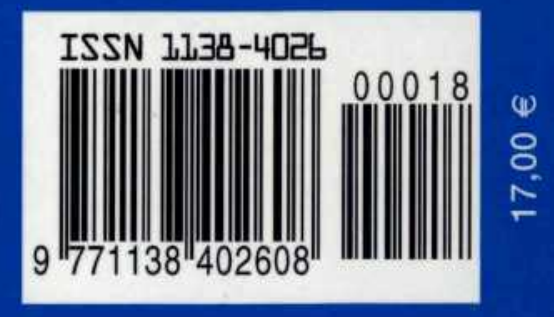

